\title{
Improving of Photovoltaic Cell Performance by Cooling using Two Different Types of Fins
}

\author{
Hussein K. Jobair \\ University of Baghdad \\ College of Engineering \\ Energy Engineering Department
}

\begin{abstract}
A numerical investigation have been executed for improving the efficiency of a photovoltaic cell by using two types of fins(rectangular and triangular)at the rear of the cell to increasing the area for losing heat. The study has been executed under a certain circumstances, the variation of a fluid velocity, fin length, fin thickness and fin spacing taken into account. Under a certain circumstances the triangular fin shows a higher ability for losing heat and higher performance than the rectangular fin. The MATLAB program used in this research to ensure the results.
\end{abstract}

\section{Keywords}

Photovoltaic cell, extended surface, triangular fin, cooling panel,

\section{INTRODUCTION}

The photovoltaic cell cooling is one of the important methods to increase the efficiency of the cell beside an increase of the power output. One of the main cooling methods used are added an expansive surfaces on the back of the cell to increase heat transfer and maintains a certain temperature level of the cell to be working optimally. In other hand, it is possible to using the heat removal in other utilizing like heating buildings or through their use in industrial applications. Anja Royne [1] investigated the Cooling of photovoltaic cells by using the concentrating systems. The model that under considerations comprise low and uniform cell temperatures, system accuracy, sufficient ability for dealing with worst cases and minimum power consumption by the system. He studied different systems of solar concentrations systems typed according to its geometry. Linxiao Zhu [2] introduces a general approach to lower the operating temperature of a solar cell, while maintaining its solar absorption at the same average. He presents an ideal scheme for the irradiative cooling of solar cells and prove that the ideal scheme can lower its operating temperature by $18.3 \mathrm{~K}$. also his investigation demonstrate that a micro-photonic design based on real material properties that approaches the performance of the ideal scheme. Also he show that the irradiative cooling effect is substantial, even in the presence of significant convection and conduction and parasitic solar absorption in the cooling layer, to achieve that he provides a sufficient thin for cooling layer. Bryce Cruey, Jordan King \& Bob Tingleff [3] investigated the cooling of a photovoltaic panel by using fins and duct putted in the rear surface of the panel, they studied the effect of various parameters of fins to the power output, a forced convection had been assumed in the rear duct of panel. Their models had been suggested that the solar concentration is maximum for air velocity in the duct. White, Chapman [4] studied the effect of heat transfer through the fins by putting the fins rear the surface of photovoltaic cell to increase the surface area for losing heat, they had been modeled a formulation by using a conduction and convection heat transfer throughout the fins, and by assume that heat transferred in one dimension and steady state condition. The results give a good approach to the temperature gradient in the fins. J.K. Tonui, Y. Tripanagnostopoulos [5] satisfied the cooling of photovoltaic cell by air with using a suspended thin flat metallic sheet at the middle or fins at the back wall of an air duct to augments heat transfer to improve the performance of solar collector. Their results of thermal efficiencies are compared with the typical PV/T air system. S.A. Kalogirou Tripanagnostopoulos [6] presents TRNSYS simulation results for hybrid PV/T solar systems for domestic hot water applications both passive (thermosyphonic) and active. Prototype models made from polycrystalline silicon (pc-Si) and amorphous silicon (a-Si) PV module types combined with water heat extraction units were tested with respect to their electrical and thermal efficiencies, and their performance characteristics were evaluated. The TRNSYS simulation results are based on these $\mathrm{PV} / \mathrm{T}$ systems and were performed for three locations at different latitudes. The results show that a considerable amount of thermal and electrical energy is produced by the $\mathrm{PV} / \mathrm{T}$ systems, and the economic viability of the systems is improved.

\section{OBJECTIVE OF RESEARCH}

From this research the effect of fins installed at the rear of a photovoltaic panel can be studied by using two types of fin to compute the efficiency and studies it effects on the performance of photovoltaic cell, in addition to that evaluate the power output and then compared the efficiency for both types under study. Fin Thickness, fin length, fin spacing and air velocity at the rear duct is taken into account in this investigation about the photovoltaic panel.

\section{GOVERNING EQUATIONS}

The procedure is used for expanding surface for a one dimensional heat transfer by assuming a steady state condition and by applying the first law of thermodynamics of a control volume. Assuming $\mathrm{q}_{\mathrm{x}}$ represents the heat conducted into a control volume, $\mathrm{q}_{\mathrm{x}+\mathrm{dx}}$ the heat conducted out of control volume; $\mathrm{dq}_{\text {conv }}$ is the heat conductive to the surrounding $[7$, 8,9 and 10].

$$
\left(\begin{array}{c}
\text { energy conducted into } \\
\text { control vloume }
\end{array}\right)=\left(\begin{array}{c}
\text { energy conducted out } \\
\text { of contrl volume }
\end{array}\right)
$$

$$
+\left(\begin{array}{c}
\text { energy convected to } \\
\text { the sorrounding }
\end{array}\right)
$$

\subsection{Assumptions}

Several assumptions that could help to find the mathematical model [11 and 12]: 
- In the analysis of fins, we consider steady operation with no heat generation

- In the fin, and we assume the thermal conductivity $\mathrm{k}$ of the material to remains constant.

- Also assume the convection heat transfer coefficient $\mathrm{h}$ to be constant and uniform over the entire surface of the fin for convenience in the analysis.

In the form of equation:

$q_{x}=q_{x+d x}+d q_{\text {conv }}$

We know that:

$q_{x}=-k A_{c} \frac{d T}{d x}$

$q_{x+d x}=q_{x}+\frac{d q_{x}}{d x} d x$

$d q_{\text {conv }}=h d A_{s}\left(T-T_{\infty}\right)$

$A_{c}$ Is a cross sectional area of the fin $A_{s}$ is a surface area of the fin and $\mathrm{T}_{\infty}$ represents the temperature of the surrounding and it's constant. Substituting equations $3,4 \& 5$ into equation (2) and simplifying [7]:

$\frac{d}{d x}\left(A_{c} \frac{d T}{d x}\right) d x-\frac{h}{k} d A_{S}\left(T-T_{\infty}\right)=0$

(6)

$\frac{d^{2} T}{d x^{2}}+\frac{1}{A_{c}} \frac{d A_{c}}{d x} \frac{d T}{d x}-\frac{1}{A_{c}} \frac{h}{k} \frac{d A_{s}}{d x}\left(T-T_{\infty}\right)=0$

Assume for simplifying the above equation that $\left(\mathrm{T}-\mathrm{T}_{\infty}\right)=$ $\theta_{\infty}, A_{s}=P x$ where $\mathrm{P}$ is the fin perimeter.

$\frac{d A_{s}}{d x}=P \quad m^{2}=\frac{h P}{k A_{c}}$

Now we have two types of fin:

a. Constant cross sectional rectangular fins Fig.1, which means that $\frac{d A_{c}}{d x}=0$ in this case equation (7) becomes [7, $8,13,14,15]$

$\frac{d^{2} \theta}{d x^{2}}-m^{2} \theta=0$

This is a linear homogenous second order differential equation with constant coefficients. The general solution for this equation is:

$\theta(x)=C_{1} e^{m x}+C_{2} e^{-m x}$

Boundary conditions:

At $\mathrm{x}=0 \rightarrow \theta=\theta_{\mathrm{b}}=\mathrm{T}_{\mathrm{b}}-\mathrm{T}_{\infty}$, At $\mathrm{x}=\mathrm{L} \rightarrow \theta=$ finite

So the solution of equation (10) with these boundary conditions is $[7,8]$ :

$\theta=\left(\theta_{L} / \theta_{b}\right) \frac{\sinh (m x)+\sinh m(L-x)}{\sinh \min L}$

$q_{f}=M \frac{\cosh (m L)-{ }^{\theta_{L}} / \theta_{b}}{\sinh (m L)}$

$M=\theta_{b} \sqrt{k A_{c} h P}$

b. Variable cross sectional rectangular fins Fig.2, Consider the triangular shaped fin shown in Figure below, The fin is $\mathrm{W}$ wide (in and out of the paper), and it is assumed that $\mathrm{W} \gg \mathrm{L} \gg \mathrm{b}$, the $\mathrm{x}$ axis base is from the tip of fin $(\mathrm{x}=\mathrm{L})$. The cross sectional area and perimeter of the fin, for these assumptions, will be $[8,16,17,18$, and 19$]$
$A_{c}=2 b W \frac{x}{L}$

$P=2(W+b) \approx 2 W$

(15)

And the dimensionless temperature is

$\theta(x)=T(x)-T_{\infty}$

The fin differential equation for a triangular uniform cross sectional will be a Bessel function type:

$x \frac{d^{2} \theta}{d x^{2}}+\frac{d \theta}{d x}-N^{2} \theta=0$

$N^{2}=\frac{h L}{k b}$

(18)

Boundary condition:

At $x=L, \theta=\theta_{b}$, At $x=0, \theta=$ finite

Solving equation (17) we found that [20]:

$\theta(x)=\frac{\theta_{b} I_{0}(2 N \sqrt{x})}{I_{0}(2 N \sqrt{L})}$

$q_{L}=\left.k A_{c} \frac{d T}{d x}\right|_{x=L}=2 L \theta_{b} \sqrt{h k b}\left[\frac{I_{1}(2 N \sqrt{L})}{I_{0}(2 N(\sqrt{L}))}\right]$

$I_{0}$ is modified zero order Bessel's function of first kind.

$I_{1}$ is modified first order Bessel's function of first kind.

\subsection{Numerical Investigations}

The energy balance for a PV panel Fig.3 \& Fig.4 with fins at a steady state is $[1,21]$ :

$I=q_{\text {radf }}+q_{\text {convf }}+q_{f}+q_{\text {radb }}+q_{\text {convb }}+P_{e}$

All terms in equation (21) computed to find the power output of the photovoltaic panel and by using some assumption to complete the solution.

$q_{\text {radf }}=\epsilon \sigma\left(T_{g}^{4}-T_{e f}^{4}\right)$

(22)

$q_{r a d b}=\epsilon \sigma\left(T_{b}^{4}-T_{e b}^{4}\right)$

(23)

$q_{\text {convf }}=h_{f}\left(T_{g}-T_{e f}\right)$

$q_{\text {convb }}=h_{b}\left(T_{b}-T_{e b}\right)$

(25)

The efficiency of photovoltaic cell can be computed from:

$\eta=\frac{P_{e}}{I}$

(26)

The fin is an extended surface begins from substrate layer at the rear surface of the panel. The temperature of environment takes into our study as $25 \mathrm{C}^{\circ}$. the other parameters that are be using in the program putted in the table (2). 


\subsection{Heat Transfer Coefficient for Front and Rear Surface Panel}

Heat transfer coefficient for an inclined plane computed from $[3,7$, and 10]:

$\bar{N} \bar{u}_{L}=\frac{h_{f} L}{k_{f}}=0.68+\frac{0.67 R a_{L}^{1 / 4}}{\left[1+\left(\frac{0.492}{P r}\right)^{9 / 16}\right]^{4 / 9}}$

Where $\overline{\mathrm{Nu}_{\mathrm{L}}}$ is Nusselt Number, $\mathrm{k}_{\mathrm{f}}$ is the thermal conductivity of the fluid, and $\mathrm{L}$ is the length of the side of the plane in the direction of fluid flow. The parameter $\mathrm{Ra}_{\mathrm{L}}$ is the Rayleigh Number averaged over the length of the surface, and is the product of the Grashof $\left(\mathrm{Gr}_{\mathrm{L}}\right)$ and Prandtl $\left(\mathrm{Pr}_{\mathrm{L}}\right)$ dimensionless numbers. The Grashof Number is the ratio between buoyancy forces and viscous forces.

$G r_{L}=\frac{g \cdot(\cos \theta) \beta \cdot\left(T_{g}-T_{e f}\right) \cdot L^{3}}{v^{2}}$

Where $\mathrm{g}$ is the gravitational constant, $\beta$ the volumetric expansion coefficient and it is equal to $1 / \mathrm{T}_{\mathrm{ef}}$, $\mathrm{L}$ is the characteristic length, $\theta$ is the angle between the zenith and the surface panel, and $v$ is the kinematic viscosity of the fluid. The Prandtl Number is found by:

$\operatorname{Pr}_{L}=\frac{v}{\alpha}$

Where $\alpha$ is the thermal diffusivity.

Equation (28) can be used for values of $\theta$ between 0 and 60 , and laminar flow conditions. The critical Rayleigh number is $[3,7,10]$ :

$R a_{\text {critical }}=3 * 10^{5} \exp (0.136 \cos (90-\theta)]$

For turbulent flow the heat transfer coefficient is:

$\overline{N u_{L}}=\frac{h_{L} L}{k_{f}}=\left[0.825+\frac{0.387 R a_{L}^{1 / 6}}{\left[1+\left(\frac{0.492}{P r}\right)^{9 / 16}\right]^{8 / 27}}\right]^{2}$

For a rear surface of the photovoltaic panel, the heat transfer coefficient can be evaluated:

$\overline{N u_{L}}=\frac{h_{b} L}{k_{f}}=0.664 * \sqrt{R e_{L}} * \operatorname{Pr}_{L}^{1 / 3}$

Where in this case the forced convection will be achieve and $\mathrm{Re}_{\mathrm{L}}$ is Reynolds number.

$\operatorname{Re}_{\mathrm{L}}=\frac{\mathrm{u} \cdot \mathrm{L}}{v}$

Where $u$ is the velocity of the fluid $(\mathrm{m} / \mathrm{s})$. Equation (32) is for laminar flow $\left(\operatorname{Re}_{\mathrm{L}}<5 * 10^{5}\right)$. for transitional flow with $5 * 10^{5}<\operatorname{Re}_{\mathrm{L}}<10^{7}$ the following equation can be used:

$\overline{N u_{L}}=\operatorname{Pr}^{1 / 3}\left(0.037 \operatorname{Re}_{L}^{0.8}-850\right)$

In this study we use the laminar flow $\left(R e_{L}<5 * 10^{5}\right)$.

\section{RESULTS AND DISCUSSION}

The results of this research were found by using MATLAB program by building a program which is dealing with a different variables and input data. The figures below shows the effect of different variables on the efficiency of photovoltaic cell, like velocity of fluid, fin thickness, fin length and fin spacing for rectangular and triangular fin and compare the results for finding the suitable shape of fin to install at the rear of the photovoltaic cell. Fig.5 shows a comparison between rectangular and triangular fin efficiency under the effects of fluid velocity, in general we can see that the efficiency of fin increases with increasing the velocity of fluid. At the same time the triangular fin have slightly much higher efficiency than the rectangular one, this quantity increasing slightly with increasing velocity of fluid until it reach the turbulent region, which is above $8 \mathrm{~m} / \mathrm{s}$ fluid velocity. This is can be available only when pump is installed to push the fluid. Still speak about fluid velocity and its effect to the another parameter, which is cell temperature as in Fig.6, as the fluid velocity increase, this is cause to cell temperature drops to lower values which is increase the panel efficiency. So from Fig.5 and Fig.6 we see that the efficiency increase with decreasing the cell temperature. This is in fact comes from that the performance of cell much better for a certain temperature values.

The effect of fin thickness to the efficiency shows in Fig.7. It is obvious that efficiency increases with increasing fin thickness, we can see also that triangular efficiency has larger value than the rectangular one at a little fin thickness, ones the thickness begin to increase, the efficiency of rectangular fin become larger than that of triangular fin, this is because of that the surface area of rectangular fin become larger and the thickness having importance in calculation as its increase.

Fig.8 represents the effect of fin thickness to the cell temperature, the cell temperature drops as the fin thickness becomes higher. There is a slightly difference between rectangular and triangular fin which gives the triangular one the preference. Fig.9 shows the effect of fin spacing to the cell efficiency. As the spacing increase and the surface area that heat loss through it decrease, the cell efficiency will decrease.

Fig.10 shows that the cell temperature starts to increase with increasing the fin spacing, this cause to decreasing in the performance of photovoltaic panel cell. Finally the discussion of the effect of fin length to the cell efficiency and temperature shown in Fig.11 and Fig.12, from Fig.11 the cell efficiency increases with fin length, this is because the surface area that through it the heat is lost becomes bigger, also we see that the triangular fin is better performance than that of rectangular fin. Fig.12 represents the effect of fin length to the cell temperature, it is obvious that cell temperature decreases as the fin length increases which is cause to the performance of cell be increases.

\section{CONCLUSIONS}

From the results of figures (5 to 12 ), the conclusions can be putted in a several points:

1. Effect of fluid velocity.

Increasing the fluid velocity from $0.25 \mathrm{~m} / \mathrm{s}$ to the turbulent region at $8 \mathrm{~m} / \mathrm{s}$ will increase the photovoltaic panel efficiency with triangular fin by $25 \%$ and for rectangular fin by $14 \%$.

Increasing the fluid velocity from $0.25 \mathrm{~m} / \mathrm{s}$ to the turbulent region at $8 \mathrm{~m} / \mathrm{s}$ causes a decreasing in a cell temperature by $23 \%$ for a photovoltaic cell with triangular fin and $27 \%$ for a photovoltaic cell with a rectangular fin.

2. Effect of fin thickness.

Increasing the fin thickness from $0.002 \mathrm{~m}$ to $0.05 \mathrm{~m}$ will increase the photovoltaic efficiency with 
triangular fin by $0.8 \%$ and for rectangular fin by $3 \%$.

Increasing the fin thickness from $0.002 \mathrm{~m}$ to $0.05 \mathrm{~m}$ causes a decreasing in a cell temperature with a triangular fin by $4 \%$ and for rectangular fin by $5 \%$.

3. Effect of fin spacing.

Increasing the fin spacing from $0.025 \mathrm{~m}$ to $0.3 \mathrm{~m}$ will decrease the photovoltaic efficiency with a triangular fin by $19 \%$ and with rectangular fin by $19 \%$.

Increasing the fin spacing from $0.025 \mathrm{~m}$ to $0.3 \mathrm{~m}$ will increase the cell temperature with a triangular fin by $28 \%$ and with a rectangular fin by $24 \%$.
4. Effect of fin length.

Increasing the fin length from $0.01 \mathrm{~m}$ to $0.1 \mathrm{~m}$ will increase the photovoltaic efficiency with a triangular fin by $13 \%$ and with a rectangular fin by $12 \%$.

Increasing the fin length from $0.01 \mathrm{~m}$ to $0.1 \mathrm{~m}$ will decrease the cell temperature with a triangular fin by $18 \%$ and with a rectangular fin by $14 \%$.

\section{RECOMMENDATIONS}

In the future works, the study of the effect of other configurations of fins, different materials can be used in manufactory extended surface, and show the effects of variation of material properties to the performance of photovoltaic cell.

Table 1. Nomenclatures

\begin{tabular}{|c|c|c|}
\hline$q_{\text {radf }}$ & Radiation heat flux at the front surface & $\left(W / m^{2}\right)$ \\
\hline$q_{\text {convf }}$ & Convection heat flux at the front surface & $\left(W / m^{2}\right)$ \\
\hline$q_{\text {radb }}$ & Radiation heat flux at the rear surface & $\left(W / m^{2}\right)$ \\
\hline$q_{\text {convb }}$ & Convection heat flux at the rear surface & $\left(W / m^{2}\right)$ \\
\hline$q_{f}$ & Heat flux through fin & $\left(W / m^{2}\right)$ \\
\hline$P_{e}$ & Electrical power & $\left(W / m^{2}\right)$ \\
\hline$I$ & Radiation intensity & $\left(W / m^{2}\right)$ \\
\hline$T_{g}$ & Glass surface temperature & $(K)$ \\
\hline$T_{c}$ & PV cell temperature & $(\boldsymbol{K})$ \\
\hline$T_{b}$ & Panel rear surface temperature & $(\boldsymbol{K})$ \\
\hline$T_{e f}$ & Front environment temperature & $(\boldsymbol{K})$ \\
\hline$T_{e b}$ & Rear environment temperature & $(\boldsymbol{K})$ \\
\hline $\boldsymbol{h}_{f}$ & Coefficient of heat transfer at the front of panel & $\left(W / m^{2} K\right)$ \\
\hline $\boldsymbol{h}_{\boldsymbol{b}}$ & Coefficient of heat transfer at the rear of panel & $\left(W / m^{2} K\right)$ \\
\hline $\boldsymbol{k}$ & Thermal conductivity & $(W / m \cdot K)$ \\
\hline$\epsilon_{f}$ & Emissivity of the front surface & dimensionless \\
\hline$\epsilon_{b}$ & Emissivity of the rear surface & dimensionless \\
\hline$\sigma$ & Stephan Boltzmann constant & $\left(5.67 * 10^{-8} \mathrm{~W} / \mathrm{m}^{2} \mathrm{~K}^{4}\right)$ \\
\hline$t$ & Thickness layer & $m$ \\
\hline$g$ & Layer of glass cover & (m) \\
\hline$a$ & Adhesive layer & (m) \\
\hline$c$ & Cell layer & (m) \\
\hline
\end{tabular}




\begin{tabular}{|c|c|c|}
\hline so & Solder layer & $(\mathrm{m})$ \\
\hline$s$ & Substrate layer & $(\mathrm{m})$ \\
\hline
\end{tabular}

Table 2.Parameters of panel and fin

\begin{tabular}{|c|c|c|c|c|c|}
\hline Parameter & Value & Unit & Parameter & Value & Unit \\
\hline$k_{g}$ & 1.4 & $W / m . K$ & $t_{a}$ & $1 \times 10^{-4}$ & $m$ \\
\hline $\boldsymbol{k}_{\boldsymbol{a}}$ & 145 & W/m.K & $t_{c}$ & $12 \times 10^{-5}$ & $m$ \\
\hline $\boldsymbol{k}_{c}$ & 145 & W/m.K & $t_{\text {so }}$ & $1 \times 10^{-4}$ & $m$ \\
\hline $\boldsymbol{k}_{\text {so }}$ & 50 & $W / m . K$ & $t_{s}$ & $2 \times 10^{-3}$ & $m$ \\
\hline $\boldsymbol{k}_{\boldsymbol{s}}$ & 120 & $W / m . K$ & $\epsilon_{f}$ & 0.855 & \\
\hline$k_{\text {fin }}$ & 120 & W/m.K & $\epsilon_{b}$ & 0.8 & \\
\hline$t_{g}$ & $3 \times 10^{-3}$ & $m$ & $I$ & 1100 & $W / m^{2}$ \\
\hline$L_{p}$ & 1 & $m$ & $w_{p}$ & 1 & $m$ \\
\hline$w_{f}$ & 1 & $m$ & & & \\
\hline
\end{tabular}

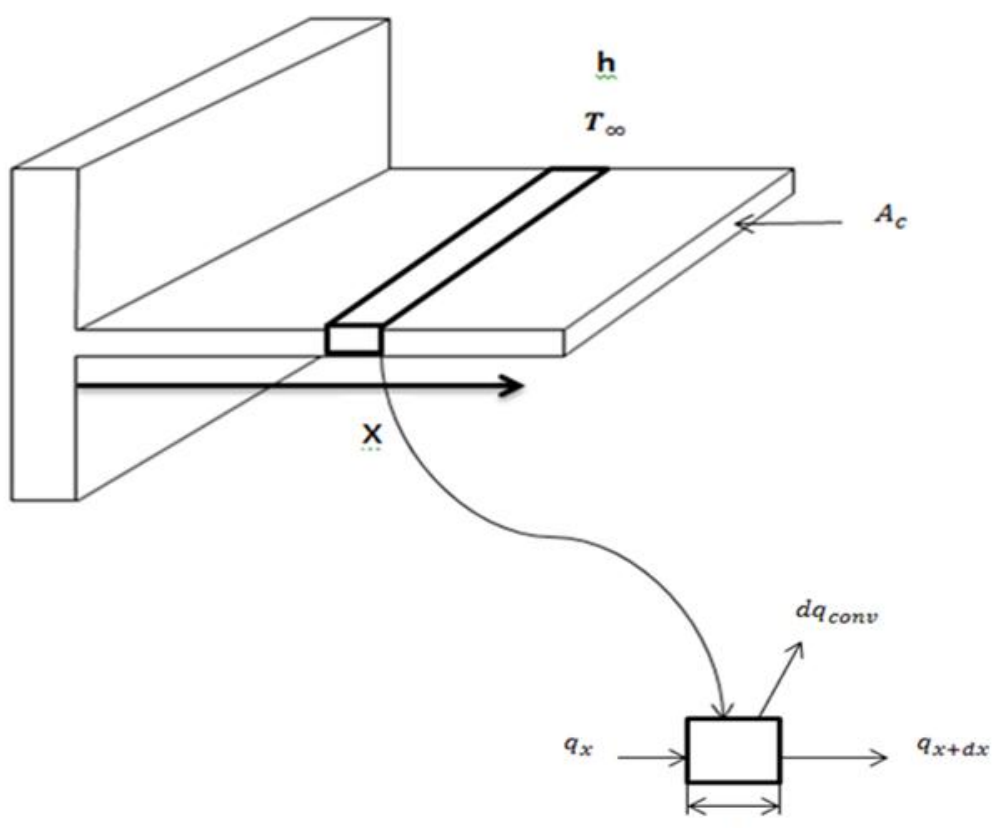

$d x$

Fig 1: Fin with a rectangular cross section.

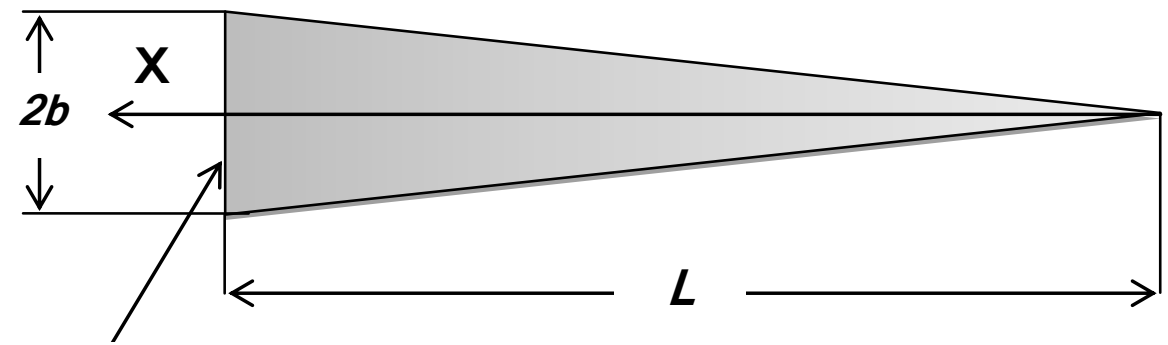

$T_{\boldsymbol{b}}$

Fig 2: Profile of triangular fin 


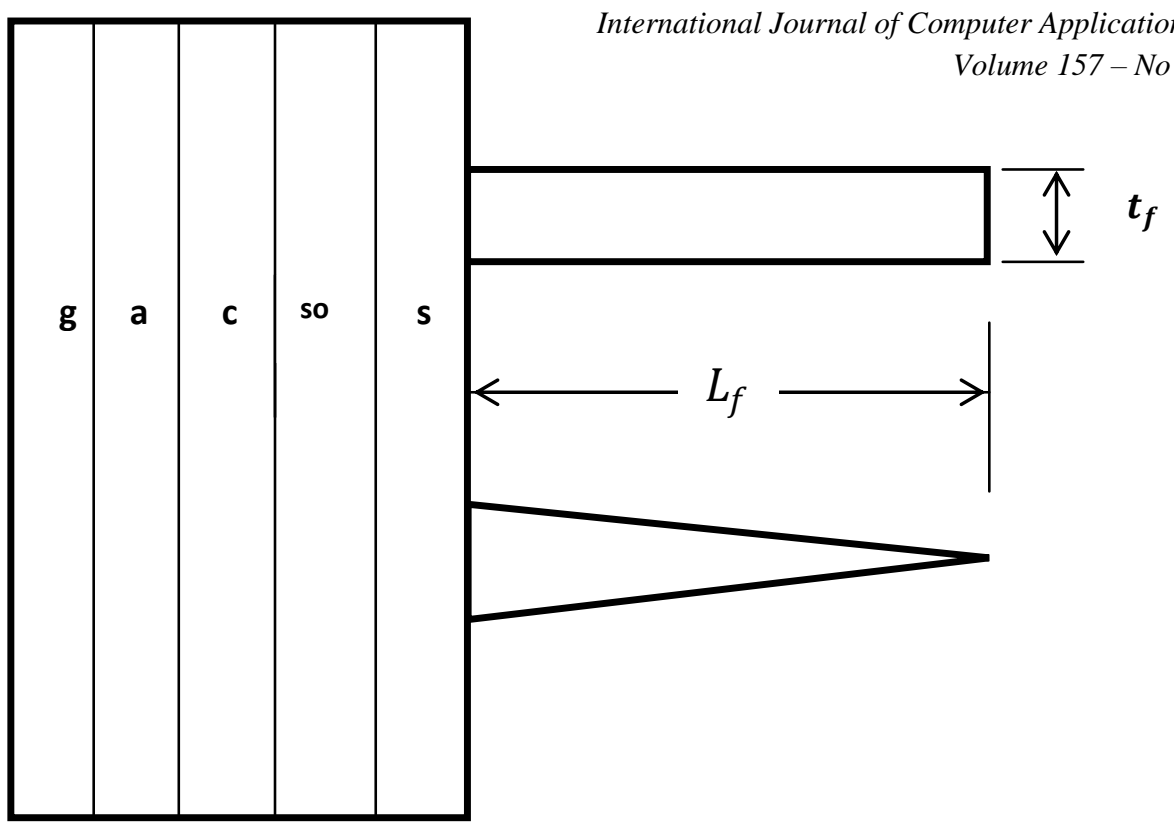

Fig 3: Layers of photovoltaic panel with fins

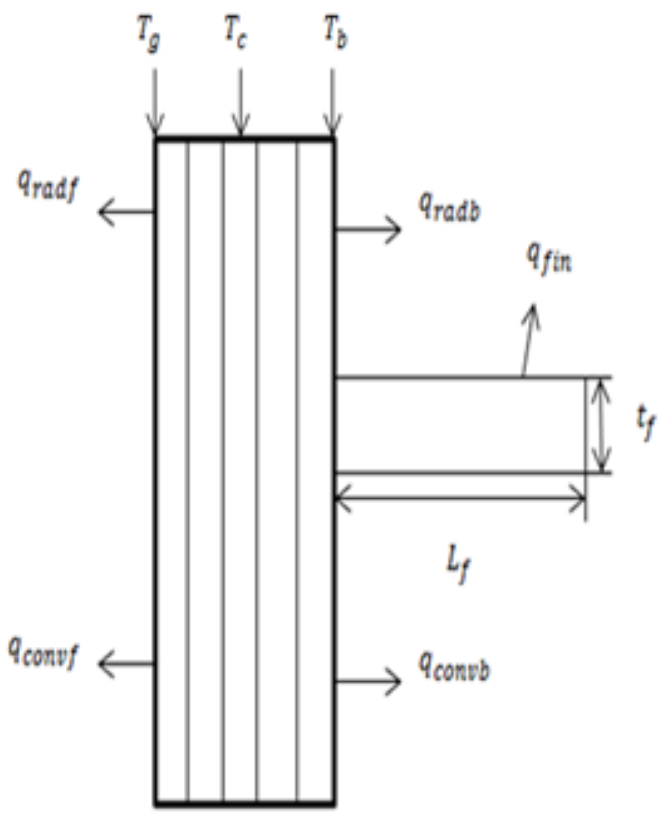

a. With rectangular fin

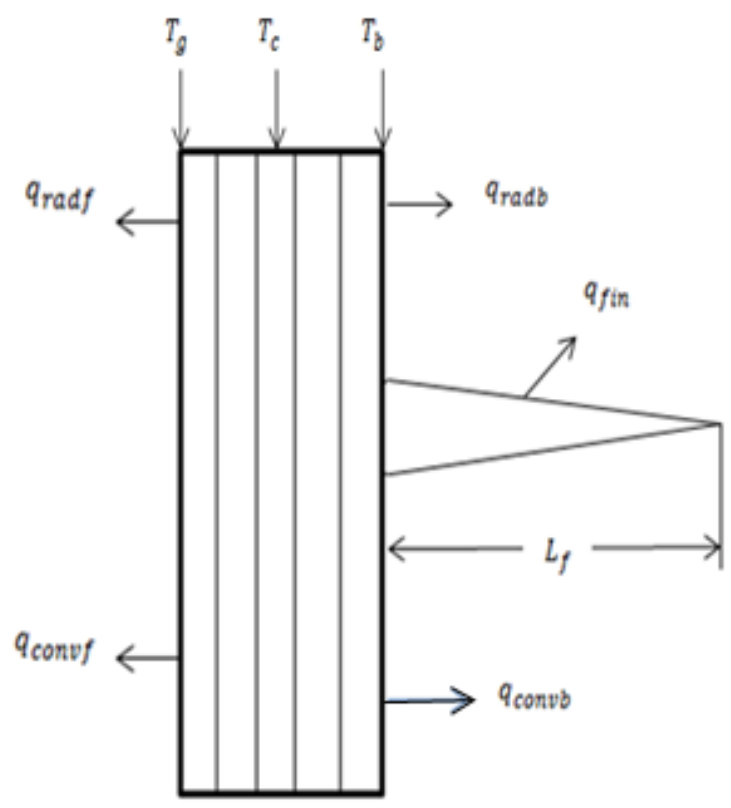

b. With triangular fin

Fig 4: Energy balance of photovoltaic cell

a. Cell with rectangular fin at the rear surface b. Cell with triangular fin at the rear surface 


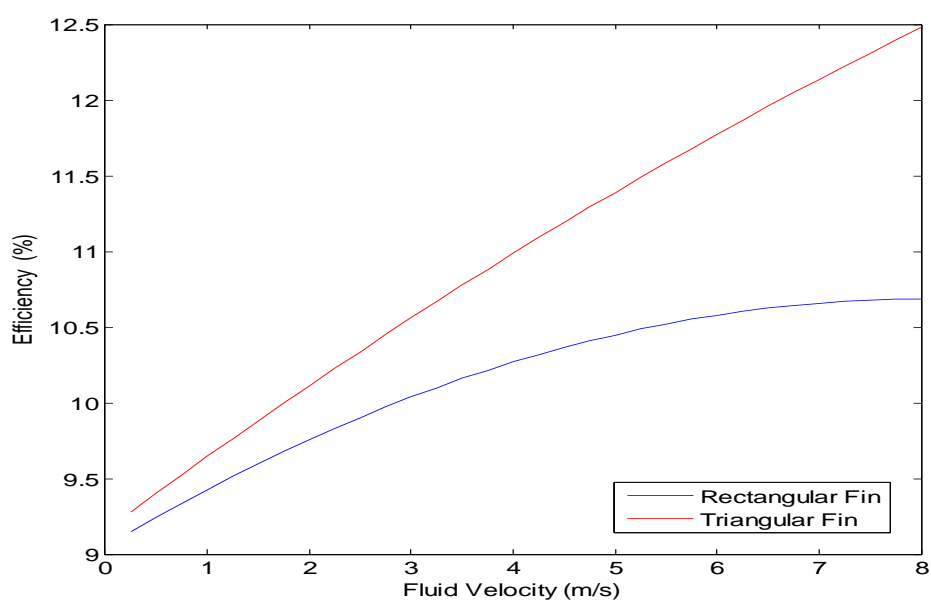

Fig 5: Effect of the fluid velocity to the cell efficiency

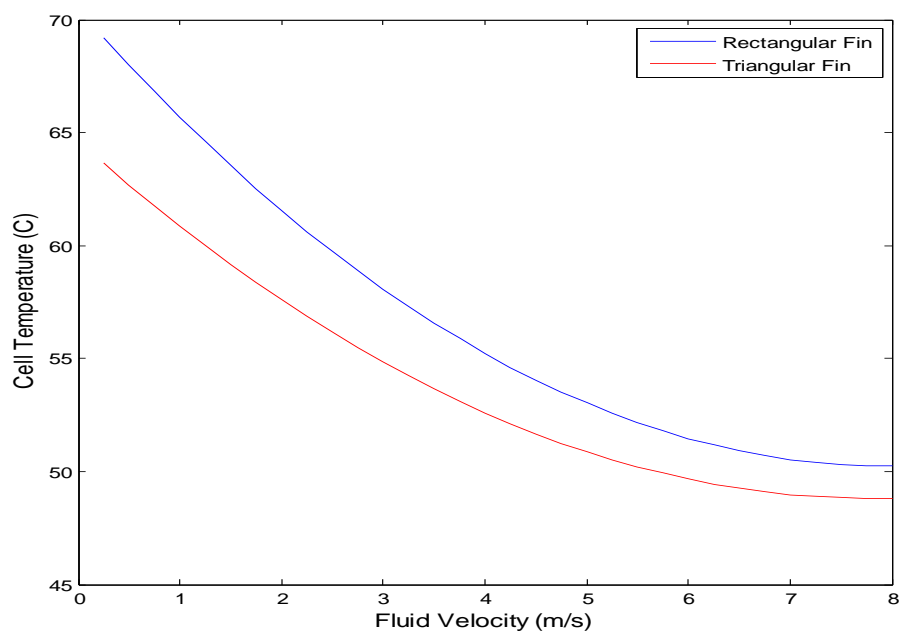

Fig 6: Effect of the fluid velocity to the cell temperature

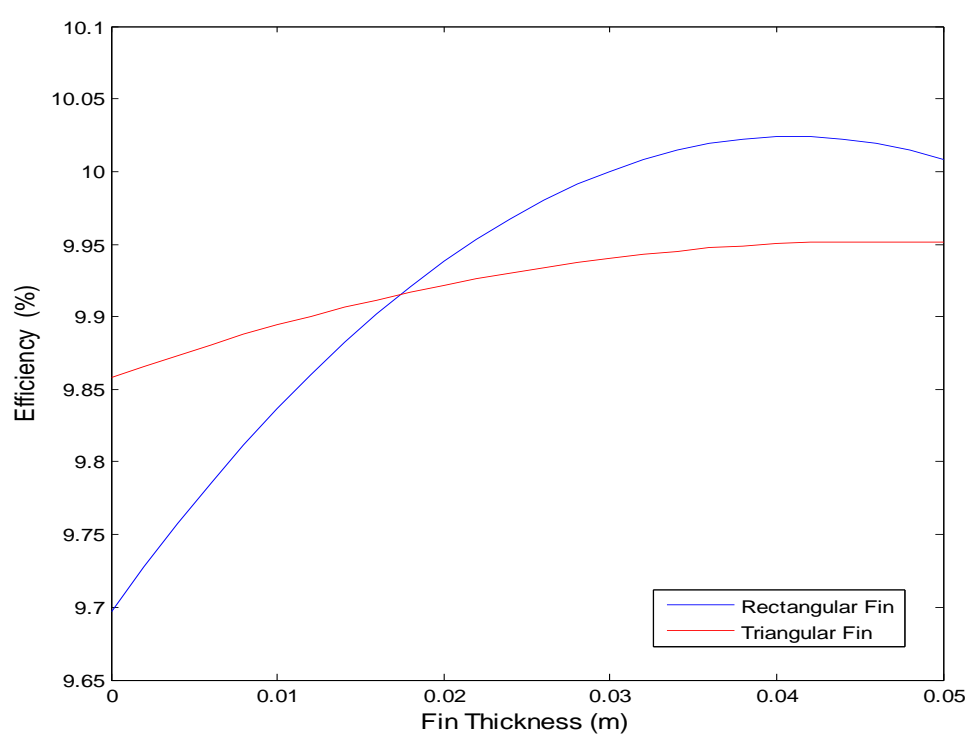

Fig 7: Effect of fin thickness to the cell efficiency 


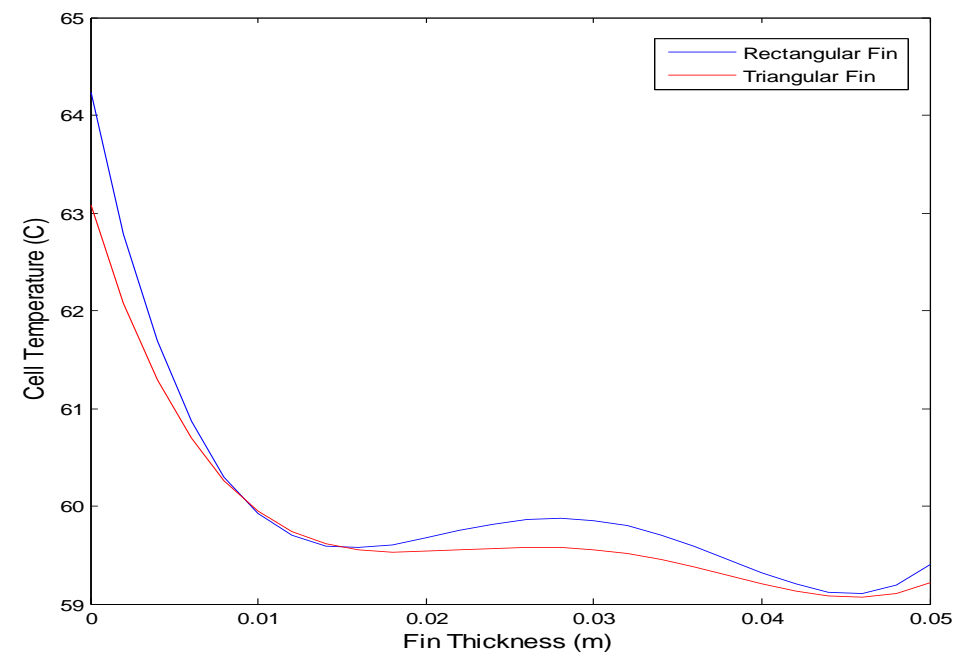

Fig 8: Effect of fin thickness to the cell temperature

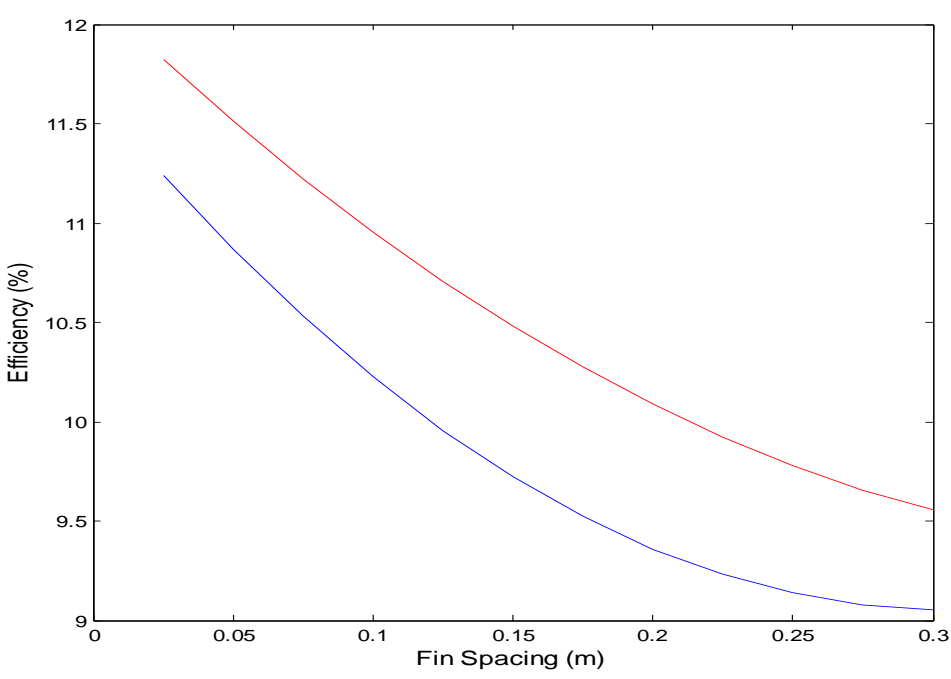

Fig 9: Effect of fin spacing to the cell efficiency

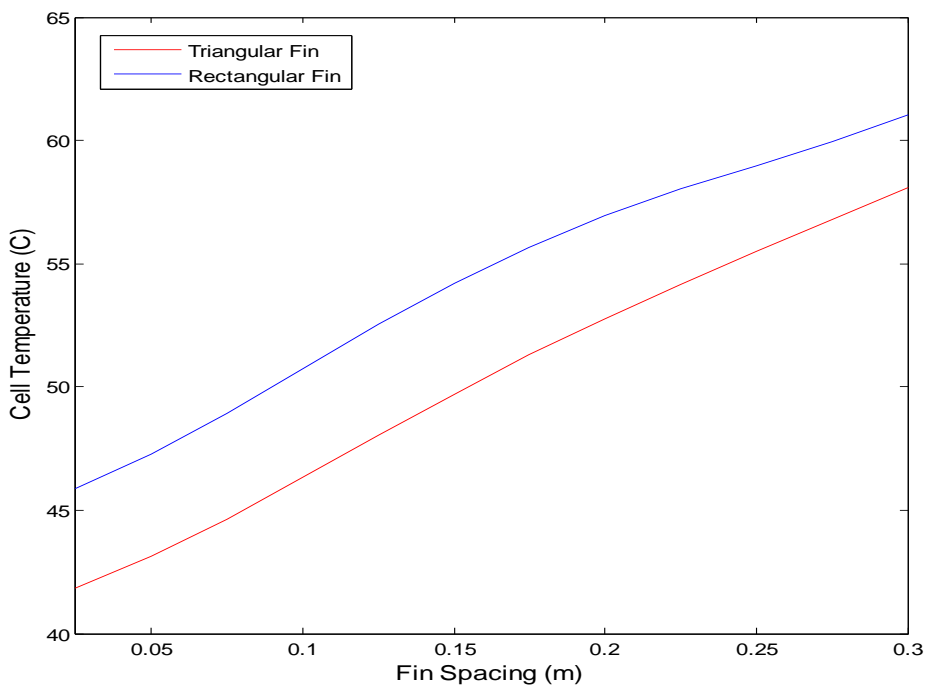

Fig 10: Effect of fin spacing to the cell temperature 


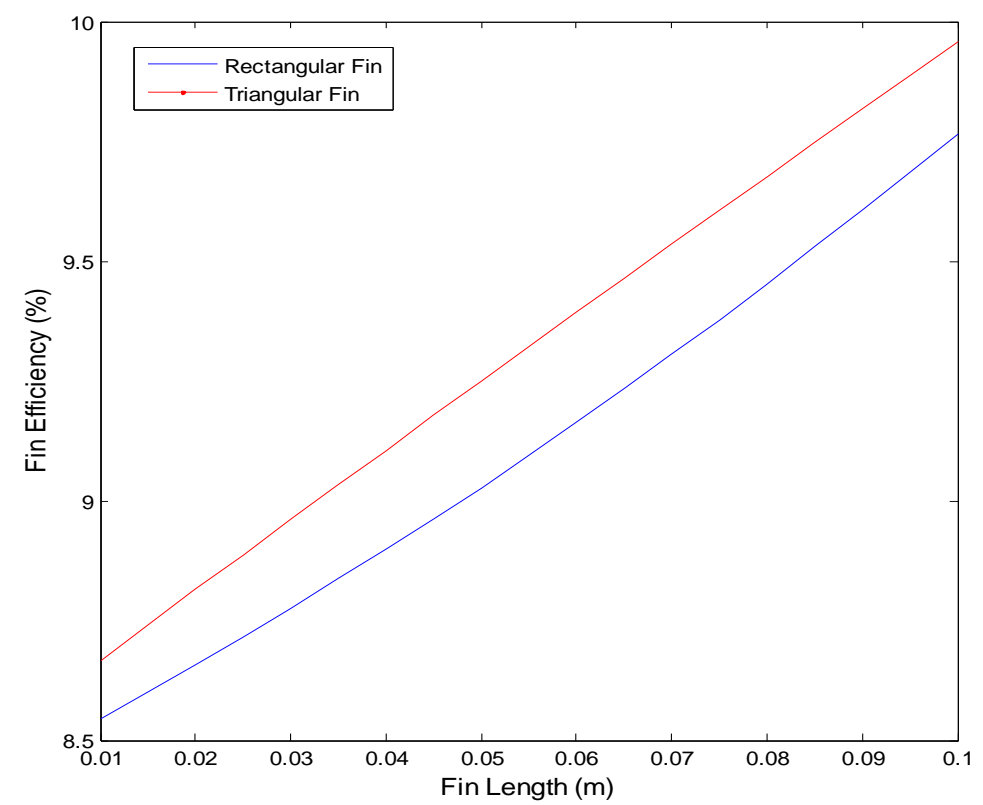

Fig 11: Effect of fin length to the cell efficiency

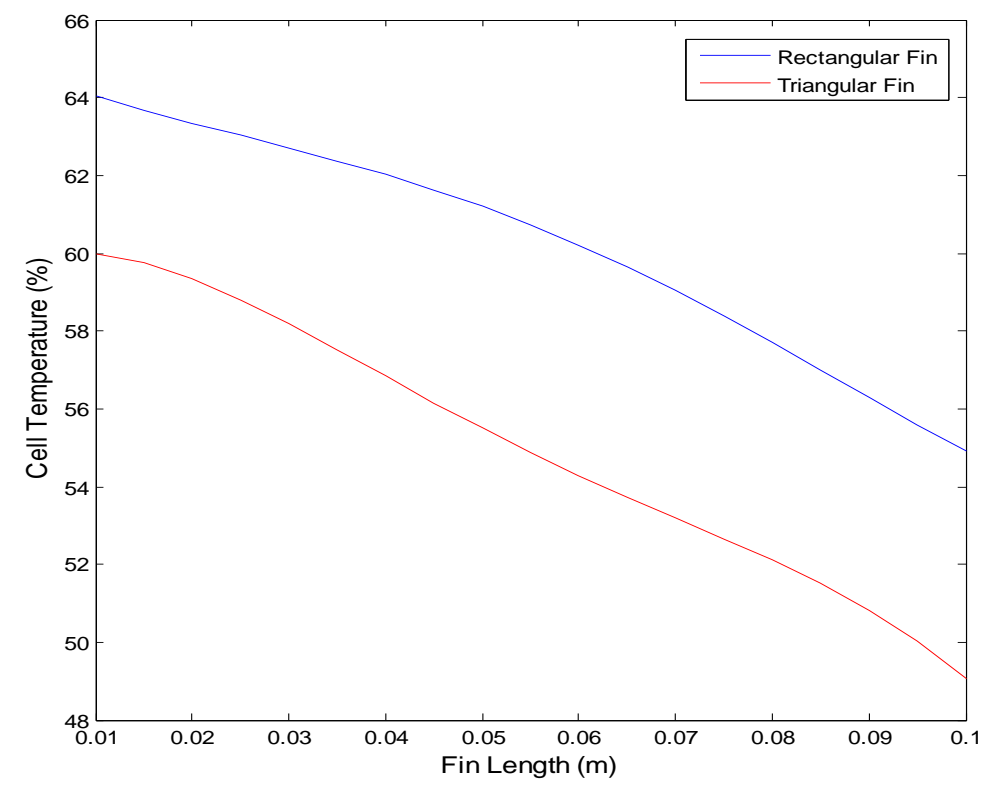

Fig 12: Effect of fin length to the cell temperature

\section{REFERENCES}

[1] Anja Royne, Christopher J. Dey, David R. Mills, "Cooling of Photovoltaic Cells under Concentrated Illumination: a Critical Review", Journals of Solar Energy Materials \& Solar Cells 86 (2005) 451-483.

[2] Linxia Zhu, Aaswath Raman, Ken Xingze Wang, Marc Abou Anoma and Shanhui Fan, "Radiative Cooling of Solar Cells", Optica, Vol.1, No.1 / July 2014.

[3] Bryce Cruey, Jordan King, Bob Tingleff, "Cooling of Photovoltaic Cells". December 7, 2006.
[4] White, F. M. (1984). Heat Transfer. Addison Weslley Publishing Company, Inc. Chapman, A. J. (1984). Heat Transfer. Macmillan Publishing Company, New York.

[5] J.K. Tonui, Y. Tripanagnostopoulos, "Improved PV/T Solar Collectors With Heat Extraction by Forced or Natural Air Circulation". Journal of Renewable Energy 32 (2007) 623-637.

[6] S.A. Kalogirou, Y. Tripanagnostopoulos, "Hybrid PV/T Solar Systems for Domestic Hot Water and Electricity Production". Journal of Energy Conversion and Management 47 (2006) 3368-3382.

[7] J.P. Holman, Heat Transfer, Tenth Edition. 
[8] Myer Kutz, Heat Transfer Calculation.

[9] Daniel W. Mackowski, Conduction Heat Transfer, Notes for MECH 7210, Mechanical Engineering Department, Auburn University.

[10] Theodore L. Bergman, Adrienne S. Lavine, Frank P. Incropera, David P. Dewitt, Fundamentals of Heat and Mass Transfer, Seventh Edition.

[11] Allan D. Kraus, Abdul Aziz, James Welty, Extended Surface Heat Transfer, a Wiley-Inter-science Publication.

[12] Pardeep Singh, Harvinder lal, Baljit Singh Ubhi, Design and Analysis for Heat Transfer through Fin with Extensions, International Journal of Innovative Research in Science, Engineering and Technology (An ISO 3297: 2007 Certified Organization) Vol. 3, Issue 5, May 2014.

[13] Innocent Rusagara, Numerical investigation of heat transfer in one-dimensional longitudinal fins, Reg.: 367545 .

[14] Sampath SS, Sawan Shetty and Chithirai Pon Selvan M. Estimation of Heat Dissipation from Plate with Multiple Tapered and Rectangular Fins. European Journal of Advances in Engineering and Technology, 2015, 2(5): 123-128

[15] J.A.Gotmare, D.S.Borkar, P.R.Hatwar, Experimental Investigation of PV Panel with Fin Cooling Under Natural Convection, International Journal of Advanced Technology in Engineering and Science. Volume No.03, Special Issue No. 02, February 2015.
[16] Sandhya Mirapalli, Kishore.P.S. Heat Transfer Analysis on a Triangular Fin. International Journal of Engineering Trends and Technology (IJETT) - Volume 19 Number 5 - Jan 2015.

[17] Jitamitra Swain, Kumar Gaurav, Dheerendra Singh, Prakash Kumar Sen, and Shailendra Kumar Bohidar, A Comparative Study on Heat Transfer in Straight Triangular Fin and Porous Pin Fin under Natural Convection, International Journal of Innovation and Scientific Research ISSN 2351-8014 Vol. 11 No. 2 Nov. 2014, pp. 611-619.

[18] Hyung Suk Kang, Optimization of a Triangular Fin with Variable Fin Base Thickness, International Journal of Mechanical, Aerospace, Industrial, Mechatronic and Manufacturing Engineering, Vol 1, No 1, 2007.

[19] Rusagara and C. Harley, A Numerical Well-Balanced Scheme for One-Dimensional Heat Transfer in Longitudinal Triangular Fins, Journal of Mathematical Problems in Engineering Volume 2013, Article ID 609536, 9 pages.

[20]Dr.somnuk Tbeerakulpisut, Application of Modified Bessel Functions in Extended Surface Heat Transfer Problems, KKU Engineering Journal Vol.22 No 1 (6174) Jan-Jull 1995.

[21] John A. Duffie, William A. Beckman, Solar Engineering of Thermal Process, Fourth Edition. 